\title{
O padrão de demanda por mão de obra na lavoura paulista e a questão do trabalhador nacional: nem vadio, nem escasso, nem instável (1890-1915) *
}

\author{
Cláudia Alessandra Tessari ${ }^{* *}$
}

\begin{abstract}
Resumo
Este artigo analisa a relação entre o padrão de demanda por mão de obra na agricultura paulista entre 1890 e 1915 e as formas de engajamento do trabalhador na atividade produtiva defendendo a ideia de que estas últimas propiciavam a formação de estereótipos sobre o chamado trabalhador nacional, tais como os da sua escassez e sua instabilidade e ociosidade.

Nas interpretações mais gerais sobre a formação econômica e social brasileira, um dado prepondera: a quase "exclusão" do brasileiro pobre do processo de produção, sendo elemento marginal e acessório na estrutura produtiva central brasileira e paulista. Mostramos que a demanda por trabalho era marcadamente sazonal e incerta gerando, com isso, necessidade de oferta elástica de trabalhadores temporários e explicando, em parte, a contradição de uma sociedade que tinha, segundo o discurso da época, ora falta de trabalhadores, ora abundância; ora trabalho, ora ociosidade.
\end{abstract}

Palavras-chave: Formação do mercado de trabalho; Trabalhador brasileiro; Sazonalidade agrícola; Vadiagem; São Paulo.

\section{Abstract \\ The standard of workforce demand in agriculture in Sao Paulo and the native worker: neither idleness nor shortage nor instability (1890-1915)}

The article examines the relationship between the demand for manpower in agriculture in the São Paulo state between 1890 and 1915, and the forms of worker involvement in productive activity. It defends the idea that it was these forms of worker involvement that formed the stereotypes about a national worker, such as the shortage of these workers, and their instability and idleness.

In the most general interpretations about the economic and social formation in Brazil, a predominant factor prevails: the "almost exclusion" of the poor Brazilian in the production process, as a marginal and accessory element in the productive structure of the export economy.

This article analyzes the demand for labor in the tillage industry in São Paulo, showing that it was seasonal and uncertain. It shows that this pattern of intermittent work explains in part the contradiction of a society that had, according to the discourse of the time: either a lack of workers, or an abundance; and at times hard workers, and at other times idle workers.

Keywords: Formation of the labor market; Brazilian worker; Agricultural seasonality; Idleness; São Paulo.

JEL N360, N560.

\footnotetext{
* Trabalho recebido em 14 de fevereiro de 2012 e aprovado em 14 de julho de 2013.

*** Professora de História Econômica da Escola Paulista de Política, Economia e Negócios da Universidade Federal de São Paulo (EPPEN-Unifesp), Osasco, SP, Brasil. E-mail: ctessari@gmail.com
} 


\section{Introdução}

Em boa parte da historiografia sobre a transição do trabalho escravo para o livre no Brasil, é enfatizada a presença do imigrante europeu na lavoura comercial para exportação e a concomitante "quase ausência" do brasileiro nesta transição (Prado Jr., 2000; Beiguelman, 1971; Franco, 1983; Kowarick, 1987).

Estudos tentaram resgatar estes "homens esquecidos" (Eisenberg, 1989; Dean, 1977) e o tema do trabalhador nacional veio recebendo mais atenção desde a década de 1990, com trabalhos sobre o imaginário ou o discurso sobre esse trabalhador (Naxara, 1998; Salles, 1995), com trabalhos de âmbito regional (Moura, 1998; Messias, 2003), no circuito urbano (Santos, 2003), ou ainda, enfocando a migração interna (Gonçalves, 2002). Acreditamos, no entanto, que mais dados podem ser acrescentados quando estudamos detalhadamente o padrão de demanda e de oferta de mão de obra do período, sendo este padrão importante para mostrar tanto o efetivo trabalho dos nacionais, quanto o modo como eles eram utilizados no mundo do trabalho, bem como para explicar a generalização por parte das fontes e da bibliografia de seu "quase não trabalho" provocado pela sua escassez, instabilidade e ociosidade.

Quando observamos o padrão de trabalho no mundo rural, percebemos que uma característica importante é que ele não é contínuo, sistemático e linear, como é o trabalho nas fábricas. Por depender demasiadamente das forças da natureza e por ser dependente do ciclo de vida de cada planta, do clima e da ação do clima sobre as plantas, o trabalho agrícola faz-se de maneira descontínua, com tarefas e ritmos diferentes ao longo do ano e alternando momentos de trabalho intenso, de pouco trabalho e de não trabalho (a vacante). Percebe-se, portanto, que havia uma alta sazonalidade na demanda por mão de obra na agricultura.

Muitos autores se referem a esta questão da sazonalidade na agricultura quando se referem ao mundo do trabalho durante a escravidão ou durante a transição para o trabalho livre sem, no entanto, colocá-la no centro da análise.

Gorender, ao descrever as leis que regiam o escravismo colonial, refere-se ao problema da sazonalidade do trabalho como um fator que agravava aquilo que o autor chamou de "lei da rigidez da mão de obra escrava": se o trabalho escravo já implicava por si só um problema de inelasticidade da mão de obra, visto que a quantidade de trabalhadores não podia se adequar aos momentos de pico e baixa demanda por trabalho, a sazonalidade do processo de produção agrícola vinha agravar ainda mais este problema (Gorender, 1985, cap. 5). Cardoso, por sua vez, argumenta que a questão da sazonalidade da economia do charque no Rio Grande do Sul implicava na extensão do trabalho do escravo como forma de compensar os momentos de pouco trabalho sendo, dessa maneira, um impeditivo à introdução de inovação tecnológica poupadora de mão de obra (Cardoso, 1997). Canabrava também faz referência ao problema da sazonalidade quando do dimensionamento 
do tamanho da plantação na lavoura algodoeira em São Paulo durante a escravidão (Canabrava, 1968).

Quanto aos autores que estudaram o período de transição da escravidão para o trabalho livre e que deram ênfase à questão da sazonalidade e suas implicações no mercado de trabalho, geralmente são aqueles analisaram a agromanufatura canavieira, seja na região Nordeste, seja no estado de São Paulo. Eisenberg mostrou a grande importância do trabalhador temporário (assalariados em geral) para o andamento regular dos trabalhos da lavoura e do engenho em Pernambuco, dadas as exigências de trabalho inconstantes mantidas pela agromanufatura canavieira, que exigiam um número bem maior de trabalhadores na época do corte e moagem quando comparado com a época da entressafra (Eisenberg, 1977).

O fato de a região Nordeste ser formada por subregiões tão diferenciadas em termos de regime pluviométrico, temperatura e vegetação (podendo-se distinguir a Zona da Mata, o Agreste, o Sertão e o Meio-Norte) implicou a formação de dois sistemas diversos de exploração agrária - o Nordeste da cana-deaçúcar e o Nordeste do gado - que, podemos dizer, têm sazonalidades diferentes e complementares entre si. A importância desta complementaridade e da migração sazonal para a sobrevivência dos dois regimes de exploração agrária foi descrita por Manuel Correia de Andrade (Andrade, 1986).

Terci estudou a utilização conjunta do colonato e de trabalhadores temporários (camaradas avulsos e sob regime de empreitada) como solução para dar conta da transição da escravidão para o trabalho livre na lavoura canavieira paulista do início do século XX (Terci, 1991). A autora mostrou também que no momento em que o mercado de trabalho ainda estava em formação e em que a sazonalidade dos trabalhos na agroindústria canavieira havia sido intensificada pela instalação dos engenhos centrais - que introduziram a inovação tecnológica na fase industrial (quando se fabrica o açúcar) sem a concomitante modernização da fase agrícola - o colonato foi um sistema de trabalho importante para manter a disciplina do trabalhador (Terci, 1991).

Se no estudo da economia canavieira, no entanto, foi dada grande importância para as exigências intermitentes de mão de obra para a análise da formação do mercado de trabalho, na economia cafeeira, por sua vez, esta questão mereceu pouca atenção. É certo que a lavoura canavieira apresenta maior sazonalidade que o café, porém, este também tem diferenças marcantes de exigências de trabalho entre uma fase e outra.

Muitos autores apontaram a questão da sazonalidade da produção de café sem, no entanto, relacioná-la mais acentuadamente ao padrão de trabalho que ela conformava (Beiguelman, 1971; Dean, 1977; Holloway, 1984; Martins, 1979; Viotti da Costa, 1977). Stolcke e Hall (1983) e Sallum Jr. (1982) são exceções entre 
os autores que estudaram a economia cafeeira. Stolcke e Hall, mesmo sem darem ênfase a esta questão, apresentam o colonato como um sistema de trabalho que satisfazia a um requisito essencial para um processo de produção que era descontínuo e sazonal: a manutenção de um exército de reserva para as épocas de colheita (Stolcke; Hall, 1983). Sallum Jr. relacionou a permissão dada ao colono e sua família ao cultivo intercalar de alimentos como uma forma de contornar um dos problemas gerados ao capital pela sazonalidade da cultura cafeeira: a garantia da subsistência do colono e do exército de reserva residente no interior da fazenda (representado pela família do colono) nos momentos em que o café não exigia trabalho (Sallum Jr., 1982).

No entanto, todos estes autores que abordaram, em maior ou menor medida, a questão das exigências sazonais de mão de obra da lavoura cafeeira, não a relacionaram de maneira direta à questão do trabalhador nacional. Esta lacuna na bibliografia veio a ser parcialmente preenchida por trabalhos mais recentes que tratam do tema do trabalhador nacional na cafeicultura do Oeste paulista. Moura analisou a forma em que a sazonalidade do trabalho na pequena lavoura de subsistência em Campinas no final do século XIX afetava o modo como os trabalhadores nacionais ofertavam sua força de trabalho para a lavoura cafeeira (Moura, 1998; Moura, 2007). Lamounier (2000) relacionou a questão da falta ou abundância de mão de obra para os trabalhos de construção de ferrovias aos períodos de picos de demanda por mão de obra nas fazendas cafeeiras. Já num segundo trabalho (Lamounier, 2007), a autora também relacionou a abundância ou escassez de mão de obra para as ferrovias aos períodos de alta ou baixa demanda por trabalho na agricultura de alimentos.

O objetivo deste artigo, portanto, é suprir esta lacuna: relacionar o padrão de demanda por mão de obra na agricultura do Oeste paulista - sazonal, descontínuo, incerto e com picos concomitantes de trabalho para as principais culturas comerciais - com os estereótipos do trabalhador nacional. Em boa medida, os argumentos deste artigo tiveram inspiração no texto de Samuel Amaral, o qual discute o padrão sazonal de demanda e oferta de trabalho nos pampas da Argentina pré-industrial (Amaral, 1998).

\section{Sazonalidade e incerteza}

Uma das características marcantes do trabalho na agricultura é sua instabilidade e incerteza. Seja ao longo do ano agrícola, seja de um ano para outro, a demanda por trabalho tem grandes oscilações. Em determinados momentos do ano, determinadas tarefas têm de ser efetuadas; em outros momentos, outras tarefas não podem ser executadas sob o risco de a planta cultivada ser perdida ou não render bons frutos. Por exemplo, uma plantação fora do tempo ideal, cuja germinação pode coincidir com momentos de calor intenso, pode comprometer o 
rendimento e a qualidade do fruto: "Essas coisas [plantar, colher, capinar, derrubar árvores, castrar animais] devem ser feitas no devido tempo para que surtam o efeito desejado" (Sobrinho, 1906, p 21).

No final do século XIX e início do XX no Brasil, a produção agrícola era ainda extremamente dependente das determinações naturais, visto que eram inexistentes as inovações químicas e genéticas que viriam alterar de certa forma o ciclo de cultivo ou a demanda por trabalho (como o uso de herbicidas, que viria diminuir a necessidade de mão de obra na capinação) (Silva, 1981, p. 33; Brant, 1977, p. 75). Essa extrema dependência implicava uma alta sazonalidade na demanda por mão de obra na agricultura, condicionando momentos de mais trabalho (especialmente a época de plantio e colheita) ou de menos trabalho (especialmente a época dos tratos culturais), e, até mesmo, momentos de vacância (quando praticamente não se trabalhava).

Em geral, os trabalhos na agricultura podem ser divididos em 4 etapas: 1) preparação do solo (quando se prepara a terra para a plantação); 2) plantação propriamente dita (por meio de sementes ou mudas); 3) trato ou cultivo (cuidados durante o crescimento e amadurecimento da planta); e 4) corte ou colheita do fruto amadurecido. Cada uma destas etapas requer tipos diversos de tarefas que devem ser realizadas com ritmos e quantidade de trabalho diferentes. No geral, a etapa do corte ou colheita é a que requer trabalho mais intenso tanto em quantidade de trabalho quanto em ritmo. Depois do corte ou colheita, a etapa que requer mais trabalho é a plantação. Por outro lado, a etapa do cultivo é a que requer menos trabalho.

A análise dos calendários agrícolas paulistas publicados nas revistas e almanaques do período mostra-nos a existência de duas estações bem marcadas: i) estação fria ou seca; e ii) estação quente ou chuvosa. Mostra-nos também que, no geral, estas duas estações apresentavam necessidades díspares de mão de obra, apesar de cada planta ter uma distribuição muito particular das tarefas ao longo dos meses do ano.

A estação fria ou seca, que em São Paulo vai de abril a setembro, era a estação de trabalho mais intenso pelo fato de nela ocorrerem as colheitas dos produtos comerciais paulistas do período (café e cana-de-açúcar). Era também nessa estação que ocorria a plantação, a outra atividade que demandava bastante trabalho. Além do mais, essa estação do ano demandava trabalho mais intenso que a estação chuvosa porque quase sempre o beneficiamento do fruto colhido ocorria concomitante à colheita.

O trabalho nessa época era intenso não só pelo fato de exigir maior quantidade de mão de obra, mas também porque o trabalho tinha de ser feito em velocidade maior, pois em geral há um limite de tempo bem definido em que o fruto maduro deve ser colhido e beneficiado, após o qual perde valor: 
[em abril] os fazendeiros de café devem abandonar tudo para colherem o café despolpado, porque há lugares em que o café amadurece de uma vez, e então torna-se impossível despolpar mais da metade da colheita; o resto só fica preparado como café ordinário que se vende pela metade ou dous terços do café lavado (Calendario Agricola, 1869, p. 49).

Além da colheita, plantação e beneficiamento, esse era também o momento adequado para o transporte das mercadorias produzidas nas fazendas e sítios. As mercadorias deviam ser transportadas rapidamente porque as estações chuvosas provocavam enchentes e alagamentos nas estradas de rodagem, dificultando o transporte das mercadorias ou tornando as estradas intransitáveis (Camargo, 1923, p. 20).

No tempo seco também deviam acontecer as mais diversas atividades não agrícolas do mundo rural, tais como os consertos e construções das instalações das propriedades e das estradas e caminhos: "São trabalhos que devem ser feitos logo, neste mês: a limpa dos pastos, a reparação das cercas, a limpeza dos tapumes [...]" (Sobrinho, 1906, p. 23). Até mesmo as obras públicas tinham de ocorrer no tempo seco. A Superintendência de Obras Públicas do Estado de São Paulo, em ofício pelo qual autorizava os consertos da estrada de rodagem que ligava a Freguesia da Água Branca à do Ò, ressalvava: "mas elles só deverão ser executados em tempo de seca, porque o tempo chuvoso não só dificulta o trabalho como também peiora as condições da estrada [...]" (Ofício, 1890)

Era nessa época, também, que devia acontecer a castração de animais, visto que a pouca umidade dificultava a proliferação de moscas e mosquitos e tornava mais fácil a cicatrização: “[...] Julho é mês proprio para corte de madeira e castração de animais da fazenda, sobretudo porcos..." (Sobrinho, 1906, p. 25).

Como a plantação deveria acontecer em Setembro, nos meses que a antecediam a terra devia ser preparada e, portanto, o preparo da terra para o plantio dos mais diversos vegetais, inclusive dos pés de café, acabava coincidindo também com o período de colheita e beneficiamento que em São Paulo ocorria entre abril e setembro.

A derrubada e a queima das matas, tarefas que antecediam a formação dos novos cafezais tinham de ser feitas também nesse período: "A época das roçadas deverá ser o periodo da sêca, isto é, quando as chuvas não possam atrapalhar esse serviço nem difficultar a queima. Prefere-se, em geral, o periodo de Maio a Agosto" (Ramos, 1923, p. 89).

Temos, portanto, que na estação fria ou seca (de abril a setembro) a demanda por trabalho era intensa. Nesse período, coincidiam as fases de colheita, plantação e o preparo do solo dos principais produtos cultivados em grande escala na lavoura paulista (café e cana-de-açúcar). Coincidiam também a castração dos 
animais, o beneficiamento e transporte dos produtos colhidos, os consertos e construções.

Por outro lado, na estação quente ou das águas (de outubro a março), o trabalho a ser realizado era bem menor. Em outubro, quando tinha início a estação quente, o trabalho começava a diminuir atingindo o nível mais baixo de necessidade de mão de obra nos meses de novembro, dezembro e janeiro, pois neste período o calor era intenso e as chuvas tornavam inviáveis diversos trabalhos:

Bem poucos são os serviços culturaes que se praticam neste mez. Não se fazem mais colheitas; as roçadas já não são possíveis; restam apenas os trabalhos de capina e alguma semeadura atrasada [...] a plantação de novembro é condemnavel por dois motivos principaes: em primeiro logar, a maturação corre risco de ser prejudicada pelo frio do outono e depois os trabalhos são muito mais custosos e incertos, devido á persistencia das chuvas. Esta plantação é forçada e só deverá ser executada em caso de força maior [...] Novembro é mau mez para chocar galinhas e castrar animais domésticos. (Sobrinho, 1906, p. 28-29).

No entanto, se a maior parte das atividades deveria acontecer no tempo seco e não na estação quente ou das águas, a lavoura de cereais (como eram chamadas as lavouras alimentares, tais como feijão, milho, batata e arroz), contrariamente, concentrava seu ciclo de produção nesta época do ano: "O único serviço que tem plena atividade neste mez é a colheita de cereaes, cultivados pela rotina" (Sobrinho, 1906, p. 29-30).

Como as chuvas faziam crescer mato e erva daninha, era neste período do ano, durante a estação das águas, que ocorriam as capinas nas lavouras comerciais de café e cana-de-açúcar, atividade importante, porém menos exigente em mão de obra: "[...] a capina ou carpa é a única operação cultural que tem justo cabimento no mez de Novembro" (Sobrinho, 1906, p. 28-29).

Portanto, quando observamos os calendários das mais diversas qualidades de plantas cultivadas no Oeste paulista em fins do século XIX e início do XX, percebemos que as demandas sazonais por trabalho que cada planta implicava, quando sobrepostas, acarretavam que, num período específico do ano (na estação fria ou seca), houvesse demanda bem maior por trabalho do que no outro período (estação quente ou chuvosa).

Um dado importante é que quando sobrepostas as exigências sazonais de trabalho da agricultura de alimentos com as da agricultura comercial (especialmente do café e cana-de-açúcar) percebe-se a não coincidência das fases de pico de trabalho na primeira com as da segunda. Os três meses de trabalho vago na lavoura de alimentos (maio, junho e julho) coincidiam justamente com os meses de trabalho intenso na cafeicultura, na lavoura canavieira e nas benfeitorias, como pode ser melhor visualizado no Quadro 1. 
Cláudia Alessandra Tessari

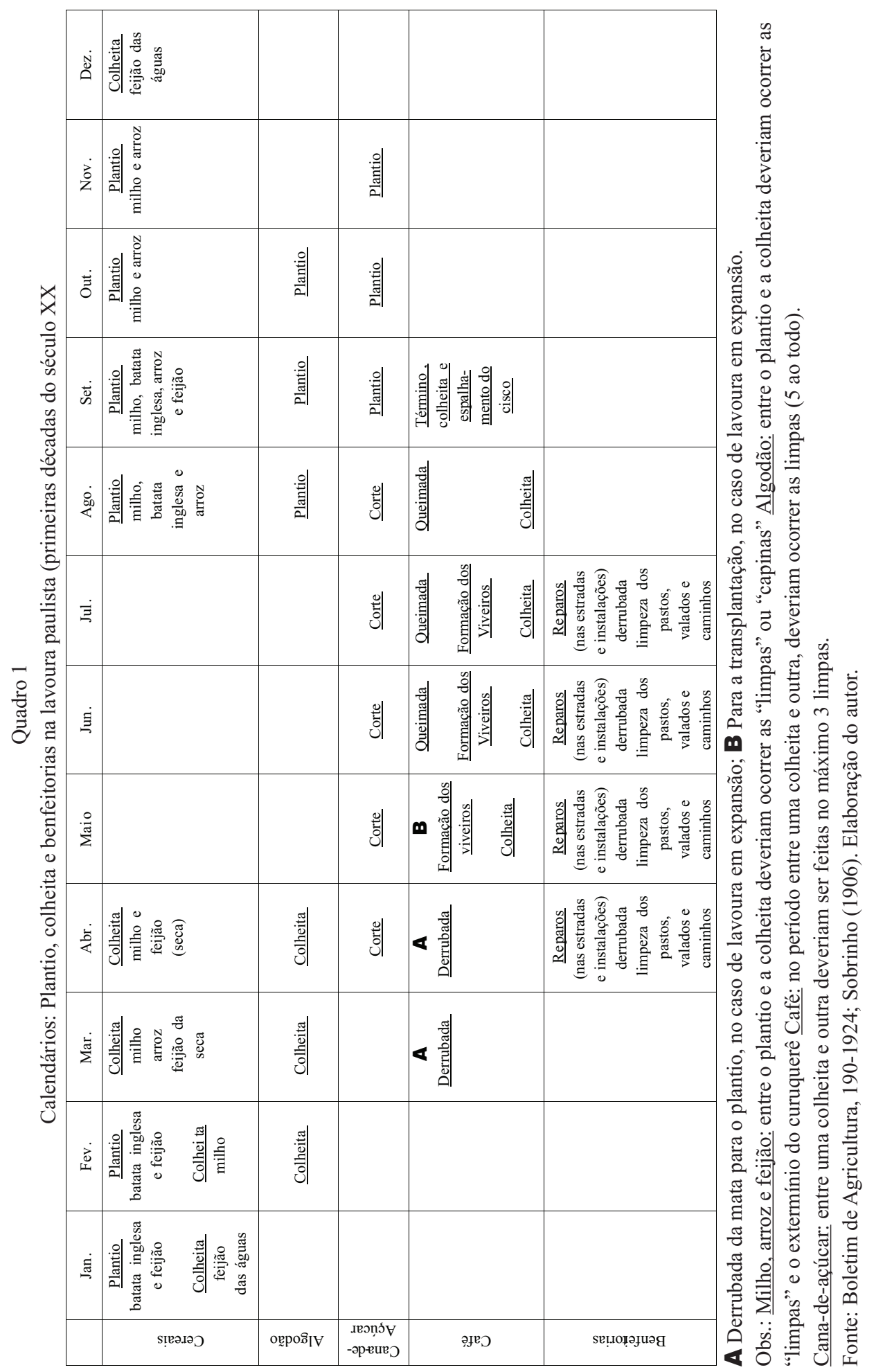


A alternância entre épocas de trabalho intenso, épocas de menos trabalho e momentos de não trabalho implicava uma característica muito peculiar à atividade agrícola: a diferença entre o tempo de trabalho e o tempo de produção. O tempo de trabalho é a quantidade de tempo que o trabalhador dedica às tarefas do processo de produção (preparar a terra, plantar, cultivar e colher), enquanto o tempo de produção é a quantidade de tempo necessária para que o produto fique pronto.

Por volta de 1915, a produção do algodão em São Paulo requeria, em média, 107 dias de trabalho, enquanto o tempo de produção era estimado em 300 dias (Albuquerque, 1983, p. 113) havendo, portanto, 193 dias de não trabalho. No caso do café, em 1888 estimava-se que o trabalhador gastaria 175 dias para tratar e colher o fruto. Estes 175 dias teriam de estar distribuídos em meio aos 360 dias decorridos entre uma colheita e outra. Portanto, o tempo de trabalho era estimado em 175 dias, o tempo de produção, em 360 e o tempo de não trabalho, estimado em 185 dias. (Gazeta de Piracicaba, 14 ago. 1888). Para a cana-de-açúcar, na época da entressafra, época entre o plantio e corte, todo o tratamento limitava-se a três capinas por ano.

Além da sazonalidade típica dos ciclos das plantas e das tarefas exigidas, outro fator que determinava a inconstância da demanda por mão de obra era a incerteza quanto à colheita, pois elas podiam variar muito de um ano para outro:

É fato sabido no campo cafeeiro: as colheitas se sucedem mas não se parecem [...] Já se viu em outro lugar como uma florada está sujeita, às vezes, a completo fracasso. Para inutiliza-la em sua quase totalidade, basta, coincidindo com o desabrocho dos botões, que sobrevenha uma chuva pesada, um prolongado vento muito frio ou que, em virtude de secas anteriores ou de uma grande colheita estejam enfraquecidas as árvores. (Ramos, 1923, p. 118).

Davatz, em 1850, chegou a afirmar que a diferença de produtividade de um ano para outro era muito considerável, sendo que "a mesma árvore, em um mau ano, produz, quando muito, a quarta parte do que dá em um ano feliz". (Davatz, 1980, p. 65; ver também Holloway, 1984, p. 119).

O regime pluvial do clima tropical de São Paulo, com suas chuvas irregulares era um agravante para a inconstância das colheitas, que eram ainda mais prejudicadas nas áreas de povoamento mais novo:

Os planaltos ocidentais de São Paulo e os do norte do Paraná apresentam em toda a sua extensão [...] um regime pluviométrico de tipo tropical indiscutível. Certamente, como sempre acontece, esse regime é acompanhado pela irregularidade das chuvas e também das colheitas. $O$ fazendeiro se compraz em afirmar, com pessimismo bem camponês, que em vinte anos não há senão quatro boas colheitas de café. (Monbeig, 1984, p. 62, grifo meu). 
A inconstância do volume a ser colhido anualmente era provocada também pelas próprias características das plantas. No café, por exemplo, era prevista certa alternância de boas e más colheitas: "É certo, porém, que mesmo na melhor época essa produtividade [do cafezal] não é idêntica todos os anos, mas intensifica-se, ao contrário, de dois em dois anos, sendo considerável a diferença entre uma boa safra e uma safra pobre" (Davatz, 1980, p. 64). A explicação para isto estava no fato de que nos anos de abundância a seiva das árvores era canalizada para a formação dos frutos, ficando os cafeeiros esgotados e sem força suficiente para formar uma boa florada que, por sua vez, resultaria nos frutos da próxima colheita (Caminhoá, 1880, p. 96).

Todas estas características do trabalho na agricultura provocavam uma grande dificuldade para estimar a quantidade de mão de obra necessária para as várias etapas do ciclo de produção, em especial para a época da colheita, momento de maior exigência de trabalho, mas também momento de maior variação do quantum de trabalho de um ano para outro. Como as colheitas podiam variar muito de um ano para outro e como os vários indícios de boa colheita podiam não se concretizar, era extremamente difícil para o fazendeiro estimar, ao certo e antecipadamente, o número de trabalhadores necessários.

Era no momento da florada, momento que marcava o início de um novo ano agrícola na cultura cafeeira, que os fazendeiros faziam novos contratos com os colonos ou renovavam os já existentes. O número de colonos contratados baseavase no número de braços necessários para manter o cafezal limpo durante a entressafra, visto que o cafezal teria de ser tratado, invariavelmente, sendo boa ou má a perspectiva de colheita (Sallum Jr., 1982; Holloway, 1984). Logo, havia diferença entre a quantidade de trabalho constante (quantidade que invariavelmente seria necessária para cuidar do cafezal na entressafra independentemente da previsão da colheita) e a quantidade de trabalho no pico, que é o quantum de trabalho necessário para colher e beneficiar o café: "O segundo embaraço resulta do desequilíbrio entre o número de trabalhadores necessários para o tratamento dos cafezaes e o reclamado pelos trabalhos das colheitas; este último muito maior". (Ramos, 1923, 104, grifo meu).

Alguns autores apontaram que o sistema de colonato tinha a vantagem de manter um exército de reserva dentro da propriedade constituído pelas mulheres e crianças (Sallum Jr., 1982; Stolcke; Hall, 1983; Rezende, 2006). No entanto, estes trabalhadores não eram suficientes para suprir toda a demanda por mão de obra. O número de colonos era contratado pelas necessidades médias do trato e não pela necessidade de pico de trabalho.

Por volta de 1900, estimava-se que para o período da colheita de café eram necessários, em média, 54\% mais trabalhadores (Estatística Especial da Lavoura de 
Café, 1900). Esses dados assemelham-se a um relatório de 1880, segundo o qual a média de trabalhadores que iam para a lavoura cafeeira continuamente era de $61 \%$ do total de trabalhadores escravos. Assemelham-se também aos dados de Bassanezi, que mostram que os colonos representavam pouco mais da metade do total de trabalhadores da fazenda Santa Gertrudes (uma grande fazenda de café no município de Rio Claro) entre 1895 e 1930 (Caminhoá, 1880; Bassanezi, 1973, 246). Para estruturar a atividade produtiva, portanto, tornava-se necessária a contratação de muita mão de obra temporária, superior a dos familiares dos colonos. (Tessari, 2010).

Esta dificuldade para mensurar a demanda por mão de obra (proveniente da incerteza e da inconstância do trabalho ao longo do ano agrícola) juntamente com o fato de o número de colonos ser estimado de acordo com as necessidades de trabalho constante, implicaram a necessidade de que trabalhadores, em não pequeno número, ficassem relegados à posição de reserva de mão de obra. Não uma reserva que viria a ser explorada apenas anos mais tarde, como muitos autores já apontaram, mas uma reserva de mão de obra para estes momentos de pico de trabalho ou, em outras palavras, trabalhadores em quantidade suficiente para tornar elástica a oferta de mão de obra.

\section{O braço escasso}

Por parte das fontes, das falas dos fazendeiros e de estudiosos dos problemas da agricultura, uma argumentação que permeou o discurso quanto à mão de obra no Brasil, durante séculos, foi a "falta de braços". Segundo eles, a população seria insuficiente em número para suprir a necessidade de mão de obra da grande lavoura. A historiografia, no entanto, já mostrou que esta tão anunciada "falta de braços" era um mito (Eisenberg, 1989, p. 223-227; Azevedo, 1987, p. 136; Castro, 1995, p. 358; Vangelista, 1991, p. 77-78). Utilizado ora para justificar a importação de mão de obra africana, ora a asiática, ora a europeia, este argumento foi acionado em épocas diferentes sempre com o mesmo fim: justificar a necessidade de trazer do exterior a mão de obra necessária para o trabalho da grande lavoura brasileira (Alencastro, 1989; Lamounier, 1988).

A análise do discurso contido na documentação evidencia, além do mais, uma contradição. Ao mesmo tempo em que alguns alegavam a "falta de braços", outros faziam referências à "abundância de trabalhadores", mostrando que as opiniões divergiam: "São Paulo precisa de braço. Precisa de braço para manter e aumentar sua lavoura [...]. É uma quantidade que pode chegar a proporções vertiginosas, conforme a opinião de cada qual e a sofreguidão dos amantes do exagero [...]". (Emigração Inter-regional para as colheitas, 1917, p. 281, grifo meu). 
Contrariando o discurso de que havia falta de braços, Daefert, diretor do Instituto Agronômico do Estado de São Paulo, tentando esclarecer a situação do mercado de mão de obra agrícola em São Paulo em 1895, notava que o problema não era a falta de trabalhadores, mas o seu excesso:

Para cultivar todos os cafezaes, cannaviais, capinzaes, etc. que existem em São Paulo, incluindo a administração, a contabilidade e o transporte local, o beneficiamento e o despacho ao mercado, são precisos 95.975 lavradores prussianos. Por que é que este mesmo serviço ocupa entre nós 1.070 .248 pessoas? (Daefert, 1895, p. 207).

O discurso da "falta de braços" não se restringia ao argumento numérico: faltariam trabalhadores também porque não se podia contar com o trabalho da população brasileira que era preguiçosa, instável e exigente:

[a população nacional] é uma população respeitavel em numero, sobria, docil e de facil direcção. Se tivermos forças dirigentes, conhecedoras do que vale a mechanica agricola, se a bondade e a energia debellarem a vadiagem, um dos maiores cancros que nos devoram, conseguiremos transformar a nossa lavoura, augmentar a riqueza e, consequentemente, proporcionar o bem estar á grande massa de brasileiros que vegeta miseravelmente, desde o Norte até o Sul. (Paes Leme, 1904, p. 219).

Como a lavoura paulista era marcada por alta sazonalidade da demanda por mão de obra ${ }^{1}$, é difícil dizer se havia ou não escassez absoluta de trabalhadores. Explicando melhor: se havia escassez, em que época ela ocorria? A noção de escassez tinha como referência o nível de trabalhadores necessários para os momentos de pico ou o nível de trabalhadores necessários para as épocas de baixa requisição de trabalho?

O que devia haver era uma escassez sazonal por mão de obra, típica de setores que necessitam de grande quantidade de trabalho apenas por um curto período de tempo, exigindo a existência de uma oferta fortemente elástica de trabalhadores para estes períodos curtos (Rangel, 2005, p. 23-80). Afinal, em economias agrícolas tipicamente sazonais "há sempre trabalhadores demais para as necessidades médias e de menos para as necessidades temporárias" (Silva, 1981, p. $51)$.

A questão da escassez sazonal de mão de obra já foi demonstrada por Maria Lúcia Lamounier. Para os trabalhos de construção das ferrovias em São Paulo, podia haver abundância de trabalhadores nos momentos em que as lavouras de alimentos e de exportação requisitavam pouco trabalho. Contrariamente, podia

(1) E por relativa sazonalidade na oferta, quando esta se referia a trabalhadores, que também cultivavam suas roças de alimentos (Moura, 1998; Moura, 2007). 
haver falta de trabalhadores nos momentos em que as tarefas na lavoura exigiam muito trabalho (Lamounier, 2000; Lamounier, 2007).

Se tivermos em mente esta questão - a da escassez sazonal de mão de obra provocada pela demanda concentrada no tempo - e analisarmos o discurso contido na documentação, perceberemos que muitas vezes a expressão falta de braços era utilizada especificamente para se referir à grande demanda por mão de obra para a colheita, época de pico de trabalho e quando não podiam faltar trabalhadores: “... o Governo, attento á necessidade de prover a lavoura de braços, não descurará os meios de evitar uma possivel crise pela escassez da mão de obra em relação a colheitas eventualmente mais abundantes." (Arantes, 1916, p. 42, grifo meu).

A "falta de braços", portanto, se realmente existisse, não devia ser generalizada, mas concentrada em períodos específicos do ano agrícola, especialmente durante a colheita, quando coincidiam várias atividades da agricultura paulista. São inúmeras as indicações na documentação de que havia, na verdade, muitos trabalhadores para determinadas fases do trabalho: "e não será o lavrador, como hoje se dá, forçado a manter durante o anno todo pessoal em excesso para se garantir nos períodos de maior movimento, nas colheitas, por exemplo." (Silva Telles, 1901, p. 6, grifo meu).

Acreditamos que era a alta demanda por mão de obra concentrada no tempo que causava um fato tão contraditório: a escassez e, ao mesmo tempo, a ociosidade do trabalhador. Ao acarretar que em determinado período as exigências de trabalho tivessem de ser supridas abundante e rapidamente, a demanda sazonal por mão de obra fazia parecer que em determinados momentos não havia gente $o$ suficiente (pelo menos não o bastante para assegurar a empresa rural contra a ameaça de ter de concorrer por mão de obra na época de pico da demanda por trabalhadores). Por outro lado, ao acarretar que em outros momentos houvesse pouco trabalho a ser realizado, toda aquela gente necessária para os momentos de pico ficava ociosa nesta etapa do ciclo de produção.

Não estamos, no entanto, afirmando que havia uma efetiva escassez de braços, mesmo para os momentos de pico de trabalho. Queremos dizer que o que acontecia era que faltavam trabalhadores em excesso, em número suficiente para garantir que as fazendas não tivessem de concorrer entre si e com outros setores por mão de obra no momento em que mais necessitavam de pessoal.

A escassez de braços tinha como ponto de referência, portanto, o exército de reserva necessário para os momentos de pico de trabalho, momento crucial para a empresa rural cafeeira, quando a falta de trabalhadores prontamente disponíveis para as fainas agrícolas poderia significar enormes perdas: "[os fazendeiros] são mais alarmados que qualquer outro pela instabilidade do trabalho agrícola, porque 
a falta de braços no momento da colheita pode ser desastrosa" (Denis, 1911, p. 226).

Em outras palavras, aqueles que afirmavam haver escassez tinham como referência a necessidade de oferta altamente elástica de mão de obra para permitir a flexibilidade de custos que uma atividade sazonal exige. $\mathrm{O}$ exército de reserva, que permitiria a total elasticidade da oferta de mão de obra, garantiria à empresa cafeeira a possibilidade de conseguir arregimentar trabalhadores de maneira intermitente, em quantidade e tempo requeridos pelo capital.

\section{O braço vadio}

Se, por um lado, os fazendeiros, seus representantes e corpo técnico apontavam a escassez de trabalhadores como justificativa para a importação de mão de obra, por outro, queixavam-se, também, da existência de abundantes turmas de vadios, ociosos, sem eira nem beira a perambular pelas cidades e estradas, sem fixar-se em trabalho algum. Aqui temos explícita a contradição de um mercado de trabalho que em um momento concentrado do ano requeria muitos trabalhadores e, em outros momentos simplesmente não necessitava deles.

Gilberto Freyre já havia chamado a atenção para uma característica comum às várias regiões americanas de colonização monocultora: o emprego do trabalhador durante uma parte do ano apenas, na outra parte ficando em um período de ócio (Freyre, 1985: XIII). Rebeca Scott, estudando a transição da escravidão para o trabalho livre em Cuba, uma economia açucareira e, portanto, com alta sazonalidade no trabalho, apontou que banir a vadiagem era "também num certo sentido contraditório, já que alguns trabalhadores estavam condenados a ficarem desempregados na entressafra" (Scott, 1991, p. 223).

Em vista do que demonstramos sobre o padrão de demanda por trabalho na agricultura do Oeste paulista da virada do século - irregular, incerto e inconstante consideramos importante acrescentar o dado da desocupação à questão da vadiagem do trabalhador nacional. Ligia Osorio Silva já havia chamado a atenção para o desemprego como motivo para a chamada vadiagem no meio urbano do período (Silva, 1983). Consideramos importante acrescentar ainda outro dado, o do desemprego sazonal provocado pela demanda inconstante por trabalho no campo. Devemos lembrar que na agricultura o trabalho regular não era predominante, muito menos o trabalho que durava o ano inteiro. Além do mais, excluindo-se os contratos de colonos, praticamente todos os outros tipos de contratos ou ajustes (verbais ou escritos) eram firmados por tarefas ou por dia de trabalho (Tessari, 2010). Portanto, a menos que o trabalhador conseguisse arranjar outra coisa para fazer entre sua dispensa e sua recontratação, ficaria desocupado. 
Nas economias agrícolas pré-industriais, a desocupação na entressafra não tinha a mesma conotação da desocupação nas economias industrializadas. Nas primeiras, marcadamente agrícolas e manufatoras, boa parte do tempo de trabalho não coincidia com o tempo de produção sendo o primeiro geralmente menor que o segundo e havendo, portanto, "tempo sobrante" durante o tempo de produção (momentos em que o processo de produção não exigia trabalho).

Nas economias pré-industriais, este "tempo sobrante" não era encarado como desemprego porque o trabalhador empregava-o na produção de artigos para sua subsistência (alimentos, seus derivados, construção civil, entre outros). No entanto, se nas sociedades pré-industriais o "tempo sobrante" não tinha a conotação de desemprego, ele tinha a de ociosidade. Quando havia a roça de subsistência e a manufatura rural acessória, alguns dos que ficavam desempregados na entressafra voltavam para os trabalhos em suas roças de alimentos, outros para os trabalhos da manufatura doméstica e, outros ainda, iam em busca de ocupações intermitentes em que pudessem se empregar no período entre as colheitas, como no trabalho da construção das ferrovias (Moura, 1998; Moura, 2007; Lamounier, 2000; Lamounier, 2007). Portanto, quando o trabalhador ainda tinha acesso à terra e quando ainda era o trabalhador que produzia grande parte de seus bens de subsistência, o desemprego sazonal não tinha a conotação de desemprego, mas de ociosidade.

Moura já mostrou que mesmo que o trabalhador estivesse trabalhando para si próprio, era comumente encarado como ocioso: "o lugar do trabalho não passava necessariamente pela fazenda ou pelas atividades institucionalizadas, mas não era assim que a elite cafeeira o concebia em termos do discurso, silenciando outras condutas, generalizando-as e metaforizando-as" (Moura, 1998, p. 255).

Ora, mas como vimos, a agricultura requer mão de obra de maneira intermitente e muitas vezes extremamente concentrada no tempo. Se a economia de determinada região fosse formada de maneira em que as várias demandas sazonais de mão de obra se intercalassem umas às outras, o emprego na região seria mais estável. Já em regiões monocultoras ou em regiões onde as principais culturas agrícolas tinham picos de trabalho concomitantes, como era o caso da maior parte das subregiões que formavam o Oeste Paulista, o problema do desemprego sazonal era maior, visto que nestas regiões a demanda por trabalho se elevava repentinamente para, num outro momento, baixar em todas as propriedades ao mesmo tempo. Desta maneira, este grande contingente de trabalhadores necessário para garantir a elasticidade da oferta de mão de obra para os momentos de pico de trabalho, ficava também ocioso, no momento da entressafra. Assim, o que muitas vezes era nomeado como vadiagem podia ser desemprego sazonal ou o resultado dele. Em relatório publicado na Gazeta de Piracicaba, o delegado de polícia do município deixava clara essa relação: 
"Em Piracicaba, em determinada fase do ano a vagabundagem é muito maior do que em outros tempos. Explica-se: o Engenho Central da Cia Sucrerie começa sua moagem em maio e termina em novembro. Durante seu funcionamento é grande o número de braços empregados, quer nos canaviais para o corte de cana, quer no próprio Engenho para o fabrico do açúcar. Assim sendo, até que recomece a moagem, encontram-se muitos indivíduos desempregados, a espera de que aquele trabalho reclame os seus serviços [...]" (Gazeta de Piracicaba, 03 abr. 1909, grifo meu).

\section{O braço instável}

Outra característica relacionada ao "trabalhador nacional" e fortemente apontada pelos fazendeiros para justificar a "quase não utilização" da mão de obra nacional foi a instabilidade destes trabalhadores que não se prestavam ao serviço regular. No entanto, estas mesmas fontes, por vezes, afirmavam que para os trabalhos mais instáveis eles eram excelentes trabalhadores: "Os caboclos e os libertos, se não oferecem um trabalho contínuo, são excelentes para os trabalhos temporários de desmatamento ou ainda para a criação e condução do gado." (Couty, 1988, p. 321, grifo meu).

A tese da instabilidade do trabalhador nacional foi utilizada como argumento para justificar a opção pelos imigrantes estrangeiros para o trabalho na lavoura cafeeira de São Paulo. O argumento central era que o trabalhador nacional era instável, não permanecendo por muito tempo num mesmo trabalho ou numa mesma propriedade e executando as tarefas de maneira sempre intermitente.

No entanto, durante o período da imigração em massa quando levas e levas de imigrantes estrangeiros chegavam a São Paulo anualmente, o problema da instabilidade foi imputado também ao colono estrangeiro. $O$ imigrante era considerado instável porque ao final de cada ano agrícola, quando vencia seu contrato, retirava-se da fazenda à procura de nova oportunidade em outro local (Petrone, 1985, p. 95-113). Esta instabilidade, considerada por alguns a mais impressionante característica da vida rural no Estado de São Paulo era causada em boa medida pela inconstância da própria demanda por mão de obra para a colheita:

Depois de uma enorme colheita como a do ano findo, e na emergencia de uma safra muito reduzida no ano seguinte, era natural que os trabalhadores das fazendas, apurados os seus pecúlios, viessem avolumar o movimento de retiradas, que anualmente, depois da colheita, se opera entre os colonos. (Secretaria dos Negócios da Agricultura, 1907, p. XIII, grifo meu).

O final da colheita era seguido por uma migração geral dos trabalhadores agrícolas, que livremente se deslocavam. Algumas estimativas chegavam a apontar que entre 40 e $60 \%$ dos colonos deixavam as fazendas anualmente (Denis, 1911, p. 207). 
Como tanto nacionais quanto estrangeiros eram considerados instáveis pelos fazendeiros, podemos questionar esta coincidência. Como vimos, o trabalho permanente (aquele que era regular ao longo do ano) não era o predominante. $\mathrm{O}$ que predominava era o trabalho irregular, aquele realizado em épocas específicas e por determinado período de tempo. Como, então, afirmar que o trabalhador era instável se o próprio trabalho era inconstante e irregular?

Quanto à instabilidade do colonato, ela era relacionada, é certo, a outras questões além da inconstância das colheitas, como, por exemplo, à fragilidade da relação entre o trabalhador e a terra, fragilidade esta criada pelo sistema de colonato. Porém, ${ }^{\mathrm{p}}$ or mais que a instabilidade do colono fosse de fato relacionada a outras questões além da inconstância da colheita, o que nos interessa aqui é destacar que, na lavoura paulista do período, todos os trabalhadores pareciam ser instáveis.

Quando Bassanezi analisou as ocupações na fazenda Santa Gertrudes, uma das mais importantes fazendas de café do Estado de São Paulo, notou correlação entre nacionalidade e tempo de permanência na fazenda. Os portugueses, os nacionais e os espanhóis eram os que permaneciam menos tempo na fazenda e os italianos e germânicos os que permaneciam mais tempo. A autora também mostrou que havia correlação entre o tipo de contrato e o tempo de permanência, sendo o camarada solteiro o mais instável (Bassanezi, 1973, p. 263-264). Estas duas relações (nacionalidade e tipo de contrato), porém, quando correlacionadas entre si, nos mostram que os nacionais eram os mais instáveis porque eram contratados justamente para as tarefas mais inconstantes: eram contratados como camaradas por dia ou por empreitada, tipos de ajustes de trabalho que permitiam ao fazendeiro desfazer-se do trabalhador a qualquer momento. (Moura, 1998; Tessari, 2010).

Messias notou que os brasileiros contratados como trabalhadores por dia eram arregimentados pelas mesmas fazendas durante anos seguidos, demonstrando que os fazendeiros não viam nesta instabilidade um problema, se não, tenderiam a contratar, em anos subsequentes, trabalhadores diferentes. Contrariamente, este era um tipo de contrato que beneficiava a própria fazenda, que podia pagar apenas pelos dias de trabalho necessários (Messias, 2003).

Muitas pessoas trabalhavam por pouco tempo em cada fazenda durante os momentos de pico de trabalho e tinham que mudar de um emprego a outro (quando conseguiam) se não quisessem ficar sem remuneração durante a entressafra.

Atribuir à mão de obra o caráter de instável, portanto, é paradoxal num mundo em que o próprio trabalho era irregular. O trabalho é que era instável, mais do que a mão de obra o era, tanto é que várias medidas sugeridas por fazendeiros, secretários de agricultura e pessoal técnico para tornar esta mão de obra "menos instável", passavam por alternativas que visavam estabilizar a demanda por trabalho e não alterar características morais do trabalhador. 
Nas discussões acerca de alternativas para solucionar o problema da instabilidade do trabalhador, as sugestões giravam em torno de medidas que resultassem na criação de oportunidades de trabalho ao longo de todo o ano agrícola, oferecendo alternativas de trabalho à mão de obra no momento de desocupação: "O recurso consistirá na vulgarização das culturas ou industrias susceptiveis de se consorciarem á exploração cafeeira. Essas culturas ou industriais deveriam utilizar a mão de obra durante 8 mezes do anno e deixa-la disponivel durante a colheita do café" (Fauchère, 1914, p. 47).

Apesar de estarmos frisando a importância de observarmos a própria instabilidade da demanda por trabalho não devemos nos esquecer que uma parte da oferta de trabalho também era instável. Esta parcela refere-se aos trabalhadores que ofereciam seu trabalho às fazendas de maneira que pudessem intercalar as tarefas na grande propriedade com as tarefas de sua roça alimentar. Moura, que estudou as relações de trabalho entre o pequeno lavrador de roças de alimentos e a grande propriedade cafeeira em Campinas, mostrou que a presença dos pequenos lavradores no mercado de mão de obra cafeeiro revelava o ajustamento de temporalidades de trabalho diferentes, conciliando o trabalho da roça ao da fazenda de café. A autora também mostrou, no entanto, que da parte dos cafeicultores isto envolveu a criação de uma série de estereótipos sobre o trabalhador nacional livre, que posteriormente foram incorporados pela historiografia (Moura, 2007, p. 96).

O conjunto da documentação investigada por Moura lhe permitiu levantar a hipótese de as razões que levavam os trabalhadores nacionais ao desvio temporário de suas obrigações estarem associadas às demandas cíclicas de trabalho nas roças de alimentos. A autora ponderou, no entanto, que esta hipótese diz respeito somente ao segmento dos lavradores que tinham acesso à terra e que ofertavam seu trabalho às grandes e médias fazendas de café, não podendo ser generalizada para o trabalhador nacional livre e pobre em geral, categoria a qual englobava diversas categorias sociais que necessitam ser melhor compreendidas em suas diferentes inserções no mercado de mão de obra livre em formação (Moura, 2007, p. 98).

A análise de Moura estava centrada, no entanto, na ótica da oferta de trabalho. Se observarmos pela ótica da demanda por trabalho e tivermos em mente a sua instabilidade na lavoura paulista do período, podemos inferir que qualquer trabalhador estava sujeito a trabalhar apenas esporadicamente, a não ser que conseguissem intercalar trabalhos com diferentes prazos de duração ou que conseguissem serviços que se sucedessem ao longo do ano.

\section{Considerações finais}

Neste artigo, portanto, tentamos mostrar que a escassez de braços, a ociosidade do trabalhador nacional e a instabilidade dos trabalhadores compunham a outra face de um mercado de mão de obra em formação, marcado 
pelas exigências altamente sazonais e incertas de trabalho numa economia agrícola pré-capitalista.

As exigências intermitentes e incertas de mão de obra se, por um lado, podem explicar em boa parte características do trabalho que eram atribuídas ao trabalhador, por outro lado podem explicar também a necessidade de manutenção de uma população ociosa que era crucial para o desenvolvimento adequado das atividades altamente sazonais.

O discurso da "falta de braços", portanto, deve ser lido também como o discurso pela necessidade de se contar com grande número de trabalhadores que estivessem disponíveis à fazenda nos momentos de pico de trabalho permitindo a flexibilidade que o capital requer numa atividade que tem um processo de produção marcado pela sazonalidade e inconstância. Seria o exército de reserva de mão de obra sazonal que permitiria que o trabalhador estivesse pronto para ser arregimentado em número suficiente, pelo prazo necessário e no momento exato em que o trabalho nas fazendas exigisse. Em outras palavras, seria ele que permitiria a constituição de uma oferta elástica de trabalhadores.

Se o capital precisa de flexibilidade de mão de obra, o capital no campo, com as características da inconstância e incerteza das exigências de trabalho, precisa mais ainda. É assim que podemos entender que, ao mesmo tempo em que havia gente ociosa, havia falta de trabalhadores.

Ao exigir quantidade e intensidade de trabalho de maneira intermitente, a agricultura gerava momentos de ócio seguidos de momentos de trabalho intenso. Nos momentos de pico de demanda de trabalho na agricultura paulista, em que eram requeridos muitos braços, parecia haver escassez de mão de obra. Nos momentos de entressafra, no entanto, sobravam trabalhadores que, se não tivessem outra atividade na qual empregar seu trabalho, ficariam "ociosos".

\section{Documentos citados}

ARANTES, Altino. Mensagem apresentada ao Congresso Legislativo, em 14 de julho de 1916, pelo Dr. Altino Arantes, presidente do Estado de São Paulo, 14 jul. 1916.

CALENDARIO AGRICOLA de S. V. Vigneron Jousselandiére. In: LOPES, Antonio de Castro. Catechismo de agricultura para uso das Escolas de Instrução primaria do Brasil. Rio de Janeiro: Typographia Americana, 1869.

CAMARGO, João Ayres de. As estradas de rodagem do Estado de São Paulo. São Paulo: Typographia Brasil de Rothschild \& Co., 1923.

CAMINHOÁ, Luiz Monteiro. Cana de assucar e café. Relatório apresentado ao Governo Imperial pelo engenheiro Luiz Monteiro Caminhoá. Rio de Janeiro: Typographia Nacional, 1880. 
COUTY, Louis. A escravidão no Brasil. Rio de Janeiro: Ministério da Cultura; Fundação Casa de Rui Barbosa, 1988.

DAEFERT, F. W. A falta de trabalhadores agrícolas em São Paulo. In: Relatório do Instituto Agronômico do Estado de São Paulo em Campinas, Colecção dos Trabalhos Agrícolas extrahidos de 1888 - 1893. São Paulo: Typographia da Companhia industrial de São Paulo, 1895.

DAVATZ, Thomas. Memórias de um colono no Brasil (1850). Belo Horizonte: Ed. Itatiaia; São Paulo: Ed. da Universidade de São Paulo, 1980.

DENIS, Pierre. Brazil 1911. London: T. Fisher Unwin Ltd., 1911.

EMIGRAÇÃO inter-regional para as colheitas. Secretaria da Agricultura, Commercio e Obras publicas do Estado de São Paulo. Boletim do Departamento Estadual do Trabalho, São Paulo, ano 7, n. 23, p. 275-283, 2º trim. 1917.

ESTATÍSTICA especial da lavoura de café nos municípios de Araçariguama, Atibaia, Bananal, Pilar, Sertãozinho e Redempção. Boletim de Agricultura. Anno de 1900. São Paulo, série 1, n. 6, 1900.

FAUCHÈRE, A. Melhoramentos possiveis diante da situação economica da cultura cafeeira no Brasil. Boletim da Agricultura. Anno de 1914. São Paulo, série 15, n. 4-5, abr./maio 1914.

GAZETA DE PIRACICABA. Piracicaba, SP: 1882-1915.

OFICIO da Superintendencia de Obras Publicas do Estado de São Paulo, 22 abr. 1890.

PAES LEME, Pedro Gordilho. Immigração. Revista Agricola, São Paulo, anno IX, n. 5, 15 abr. 1904 .

RAMOS, Augusto. O café no Brasil e no estrangeiro. Rio de Janeiro: Pap. Santa Helena, 1923.

SECRETARIA dos Negocios da Agricultura, Commercio e Obras Publicas do Estado de São Paulo. Relatorio apresentado ao Dr. Jorge Tibiriçá, presidente do Estado de São Paulo pelo Dr. Carlos Botelho, Secretario da Agricultura. Anno 1906. São Paulo: Typographia Brazil de Carlos Gerke, 1907.

SECRETARIA da Agricultura, Commercio e Obras Publicas do Estado de São Paulo. Boletim da Agricultura, São Paulo, 1900 a 1924.

SILVA TELLES, Augusto C. A producção brazileira. Revista Agrícola, São Paulo, n. 66, p. 1-7, 15 jan. 1901.

SOBRINHO, Julio Brandão (Org.). Almanach Ilustrado do Lavrador Paulista para 1905 organizado por Julio Brandão Sobrinho, inspector do $1^{o}$ distrito agronomico. São Paulo: Duprat \& Comp., 1905. 
O padrão de demanda por mão de obra na lavoura paulista e a questão do trabalhador nacional...

SOBRINHO, Julio Brandão (Org.). Almanach Ilustrado do Lavrador Paulista para 1906 organizado por Julio Brandão Sobrinho, inspector do $1^{o}$ distrito agronomico. São Paulo: Duprat \& Comp., 1906.

\section{Referências bibliográficas:}

ALBUQUERQUE, Rui Henrique Pereira Leite de. Capital comercial, indústria têxtil e produção agrícola: as relações de produção na cotonicultura paulista, 1920-1950. São Paulo: Hucitec; Brasília: Conselho Nacional de Desenvolvimento Científico e Tecnológico, 1983.

ALENCASTRO, Luiz Felipe de; CATELLI, Roberto. Trabalho escravo e trabalho compulsório no Brasil: 1870-1930. Relatório de pesquisa Cebrap (1987-1989), 1989.

AMARAL, Samuel. The rise of capitalism on the Pampes. The estancias of Buenos Aires, 1785-1870. Cambridge University Press, 1998.

ANDRADE, Manuel Correia de. A terra e o homem do Nordeste: contribuição ao estudo da questão agrária no Nordeste. São Paulo: Atlas, 1986.

AZEVEDO, Célia Maria Marinho de. Onda Negra, Medo Branco - o negro no imaginário das elites - século XIX. Rio de Janeiro: Paz e Terra, 1987.

BASSANEZI, Maria Silvia C. Beozzo. Fazenda de Santa Gertrudes. Uma abordagem quantitativa das relações de trabalho em uma propriedade rural paulista. 1895-1930. Tese (Doutoramento)-FFCL/Unesp, Rio Claro, SP, 1973.

BEIGUELMAN, Paula. A formação do povo no complexo cafeeiro. Aspectos políticos. São Paulo: Edusp, 1971.

BRANT, Vinícius Caldeira. Do colono ao boia-fria: transformações na agricultura e constituição do mercado de trabalho na Alta Sorocabana de Assis. Estudos Cebrap, São Paulo, n. 19, p. 37-92, 1977.

CANABRAVA, Alice. A grande lavoura. In: HISTÓRIA Geral da Civilização Brasileira. Brasil Monárquico. São Paulo: Difusão Européia do Livro, 1968. Tomo 2, v. 4.

CARDOSO, Fernando Henrique. Capitalismo e escravidão no Brasil Meridional. O negro na sociedade escravocrata do Rio Grande do Sul. São Paulo: Paz e Terra, 1997.

CASTRO, Hebe Maria, MATTOS G. de. Das cores do silêncio: os significados da liberdade no Sudeste escravista. Brasil, século XIX. Rio de Janeiro: Arquivo Nacional, 1995.

DEAN, Warren. Rio Claro: um sistema brasileiro de grande lavoura, 1820-1920. Rio de Janeiro: Paz e Terra, 1977.

EISENBERG, Peter L. Modernização sem mudança: a indústria açucareira em Pernambuco, 1840-1910. Rio de Janeiro: Paz e Terra; Campinas, SP: Unicamp, 1977.

Homens esquecidos: escravos e trabalhadores livres no Brasil - séculos XVIII e XIX. Campinas, SP: Editora da Unicamp, 1989. 
FRANCO, Maria Sylvia de Carvalho. Homens livres na ordem escravocrata. São Paulo: Kairós Livraria Editora, 1983.

FREYRE, Gilberto. Nordeste: aspectos da influência da cana sobre a vida e a paisagem do Nordeste do Brasil. Rio de Janeiro: José Olympio, 1985.

GONÇALVES, Paulo César. Migração e mão de obra. Retirantes cearenses na economia cafeeira do Centro-Sul (1877-1901). Dissertação (Mestrado)- FLCH/USP, São Paulo, 2002.

GORENDER, Jacob. O escravismo colonial. São Paulo: Ática, 1985.

HOLLOWAY, Thomas H. Imigrantes para o café: café e sociedade em São Paulo, 18861934. Rio de Janeiro: Paz e Terra, 1984.

LAMOUNIER, Maria Lúcia. Da escravidão ao trabalho livre (a lei de locação de serviços de 1879). Campinas, SP: Papirus, 1988.

Ferrovias, agricultura de exportação e mão de obra no Brasil no século XIX. História Econômica \& História de Empresas, v. 3, n. 1, p. 43-76, 2000.

Agricultura e mercado de trabalho. Trabalhadores brasileiros livres nas fazendas de café e na construção das ferrovias em São Paulo, 1850-1890. Estudos Econômicos, São Paulo, v. 37, n. 2, p. 353-372, abr./jun. 2007.

KOWARICK, Lúcio. Trabalho e vadiagem. A origem do trabalho livre no Brasil. São Paulo: Brasiliense, 1987.

MARTINS, José de Souza. O cativeiro da terra. São Paulo: Livraria Editora Ciências Humanas, 1979.

MESSIAS, Rosane Carvalho. O cultivo do café nas bocas de sertão paulista. Mercado interno e mão de obra no período de transição: 1830-1888. São Paulo: Ed. da Unesp, 2003.

MONBEIG, Pierre. Pioneiros e fazendeiros de São Paulo. São Paulo: Hucitec/Polis, 1984.

MOURA, Denise A Soares de. Saindo das sombras: homens livres no declínio do escravismo. Campinas, SP: Área de Publicações CMU/Unicamp, 1998.

Cafeicultores e lavradores de roças de alimentos na transição do trabalho escravo ao livre (Campinas, 1850-1888). América Latina en la Historia Económica, México, v. 27, p. 79-110, jan./jun. 2007.

NAXARA, Márcia Regina Capelari. Estrangeiro em sua própria terra: representações do brasileiro, 1870/1920. São Paulo: Annablume, 1998.

PETRONE, Maria Tereza Schorer. Imigração. In: HOLANDA, Sergio Buarque de. História geral da civilização brasileira. Brasil Republicano tomo 3, v. 2. São Paulo: Difel, 1985.

PRADO JR., Caio. Formação do Brasil contemporâneo: Colônia. São Paulo: Brasiliense Publifolha, 2000. 
O padrão de demanda por mão de obra na lavoura paulista e a questão do trabalhador nacional...

RANGEL, Ignácio. A questão agrária brasileira. In: BENJAMIM, César. (Org.). Ignácio Rangel. Obras reunidas, v. 2. Rio de Janeiro: Contraponto, 2005.

REZENDE, Gervásio Castro de. Políticas trabalhista, fundiária e de crédito agrícola no Brasil: uma avaliação crítica. Revista de Economia e Sociologia Rural. Rio de Janeiro, v. 44, n. 1, p. 47-78, jan./mar. 2006.

SALLES, Iraci Galvão. República: a civilização dos excluídos (representações do trabalhador nacional. 1870-1920). Tese (Doutoramento)- FFLCH/USP, São Paulo, 1995.

SALLUM Jr., Brasilio. Capitalismo e cafeicultura: oeste paulista, 1888-1930. São Paulo: Duas Cidades, 1982.

SANTOS, Carlos José Ferreira dos. Nem tudo era italiano. São Paulo e pobreza: 18901915 São Paulo: Annablume/Fapesp, 2003.

SCOTT, Rebecca J. Emancipação escrava em Cuba: a transição para o trabalho livre, 18601899. Rio de Janeiro: Paz e Terra; Campinas, SP: Unicamp, 1991.

SILVA, José Graziano da. Progresso técnico e relações de trabalho na agricultura. São Paulo, Hucitec, 1981.

SILVA, Ligia Maria Osório. Comentário ao texto de Boris Fausto Controle Social e criminalidade em São Paulo (1890-1924). In: PINHEIRO, Paulo Sérgio (Org.). Crime, violência e poder. São Paulo: Brasiliense, 1983.

STOLCKE, Verena; HALL, Michael. A introdução do trabalho livre nas fazendas de café de São Paulo. Revista Brasileira de História, São Paulo, v. 3, n. 6, p. 80-120, set. 1983.

TERCI, Eliana Tadeu. A agroindústria canavieira de Piracicaba: relações de trabalho e controle social (1880-1930). Dissertação (Mestrado)-São Paulo, PUCSP, 1991.

TESSARI, Cláudia Alessandra. Braços para colheita: sazonalidade e permanência do trabalho temporário na agricultura paulista (1890-1915). 2010. Tese (Doutoramento)Instituto de Economia. Universidade Estadual de Campinas, Campinas, SP, 2010.

VANGELISTA, Chiara. Os braços da lavoura. Imigrantes e "caipiras" na formação do mercado de trabalho paulista (1850-1930): São Paulo: Hucitec/Instituto Italiano di Cultura/Instituto Cultural Ítalo-Brasileiro, 1991.

VIOTTI DA COSTA, Emília. Da Monarquia à República: momentos decisivos. São Paulo: Grijalbo, 1977. 